\title{
PENGEMBANGAN PERANGKAT PEMBELAJARAN MATEMATIKA BERDASARKAN KERANGKA KERJA TPACK UNTUK MENGOPTIMALKAN KEMAMPUAN PENALARAN DEDUKTIF
}

\author{
Gusnidar $^{1}$, Sutrisno $^{2}$, Syaiful $^{3}$ \\ ${ }^{1,2,3}$ Magister Pendidikan Matematika, Universitas Jambi \\ E-mail:gusnidarspd24@gmail.com ${ }^{1)}$
}

Received 29 September 2018; Received in revised form 5 November 2018; Accepted 28 December 2018

\begin{abstract}
The objective of this research is to develop learning tools in the form of Learning Implementation Plans $(R P P)$ and Student Worksheets (LKPD) in the form of flip page ebooks, and implementmathematical learning tools and analyze the interrelationships between TPAK compiler components.This research method is a research research based on TPACK-based learning activities focused on developing learning implementation plans (RPP) and Student Worksheets (LKPD) in the form of flip page ebooks using Page flip Professionals in LKPD utilizing videos and animations. On the subject matter of mathematics subjects for students of SMP Negeri 5 Batang Hari To optimize students' reasoning abilities.The results of this study, learning devices Learning Implementation Plan (RPP) and Student Worksheets (LKPD) in the form of a flip page ebook using Page flip Professional software. The results of the analysis of TPACK linkages. The total effect on $C K, T K, P K$, on reasoning abilities as follows. $C K=$ direct $C K+$ indirect $C K$ $=0.314$. Total TK influence on deductive reasoning ability of Direct $T K+$ Indirect $T K=0.113$. So the effect of total TK on deductive reasoning abilities is 0.113 . The influence of total PK on deductive reasoning ability Direct Field + Indirect $P K=0.114$ So the effect of $P K$ on the ability of deductive reasoning is 0.114.It can be concluded that mathematical learning devices have been produced based on the TPACK framework.
\end{abstract}

Keywords: Deductive Framework Learning; Learning Optimizing Reasoning Student; TPACK

\section{PENDAHULUAN}

Lingkaran merupakan geometri bangun datar yang dipelajari di sekolah menegah pertama (SMP).Geometri bangun datar merupakan salah satu pokok bahasan yang sangat penting untuk dipelajari. Materi lingkaran banyak ditemui dan dimanfaatkan dalam kehidupan sehari-hari misalnya alat olah raga, arsitektur, dan teknologi.

Membutuhkan penalaran yang baik, untuk menemukan rumus-rumus maupun untuk menemukan sifat-sifat yang digunakan dalam menyelesaikan soal. Dalam menyelesaikan soal tidak hanya sekedar hafal rumus maupun sifat-sifat yang berkaitan, tetapi alur pemikiran dan penalaran siswa sangat diperlukan.
Penalaran deduktif adalah proses penalaran dari satu lebih pernyatan untuk mengenai apa yang diketahui untuk mencapai kesimpulan yang logis (Soleh, dkk: 2014 Dengan penalaran siswa dapat mengajukan dugaan kemudian menyusun bukti dan melakukan manipulasi terhadap permasalahan matematika serta menarik kesimpulan dengan benar dan tepat. Berdasarkan salah satu tujuan mata pelajaran matematika di sekolah adalah menggunakan penalaran pada pola dan sifat, melakukan manipulasi matematika dalam membuat generalisasi, menyusun bukti, atau menjelaskan gagasandan pernyataan matematika (Soleh, dkk: 2014).

Berdasarkan hasil penelitian Puspitarini, dkk (2013) dengan 
penelitian Pemodelan Technological Pedagogical Content Knowledge (TPACK) Berbasis Teknologi Informasi dan Komunikasi (TIK) Dengan Pendekatan Structural Equation Modeling (SEM) bahwa hasil penelitian ini mengenai variabel TPACK yang paling berpengaruh. Penelitian lain yang dilakukan Sumarsono, dkk (2012), meneliti tentang penerapan kerangka "TPACK" dan konten pembelajaran "blended learning" dapat meningkatkan aktifitas pembelajaran mahasiswa.

Penelitian tentang TPACK
merupakan
merupakan kerangka kerja guru/pendesain dalam mengintegrasikan TIK dalam pembelajaran yang dikembangkan oleh Koehler dan Mishra (Sutrisno, 2012). TPACK menekankan hubungan antara teknologi, materi dan pedagogi yang berinteraksi satu sama lain untuk menghasilkan pembelajaran berbasis TIK. TPACK merupakan pembelajaran yang memanfaatkan teknologi yang hasilnya sangat baik untuk memahami konsep materi (Lu, 2014; Atasoy, Uzun, Aygun, 2016; Jaipan-Jamani, 2018; Goradia, 2018)

TPACK merupakan kerangka kerja yang kompleks dan salingberhubungan antara komponen penyusunnya yaitu $(\mathrm{T}),(\mathrm{P})$, dan $(\mathrm{K})$ dalamproses pembelajaran.Hal ini menekankan hubungan dan kompleksitasantara tiga komponen sehingga terdapat keterkaitan antara (PCK), (TCK)dan (TPK) (Sutrisno, 2012). Dengan adanya keterkaitan antara ketiga komponen tersebut memberikan sumbangan yang amat besar terhadap perubahan dan paradigma pembelajaran.

Dalam kerangka kerja TPACK, materi pembelajaran dikemas dengan menggunakan model pembelajaran yang sesuai dengan karakteristiknya dan dipadukan dengan teknologi. Model pembelajaran merupakan kerangka konseptual yang melukiskan prosedur yang sistematis dalam mengorganisasikan pengalaman belajar untuk mencapai tujuan belajar.

Berdasarkan wawancara yang dilakukan dengan beberapa siswa diSMP Negeri 5 Batanghari. Diperoleh informasi bahwa dalam belajar siswa banyak yang tidak bisa menyelesaikan permasalahan di dalam materi lingkaran salah satunya satunya karena sulit dalam menggunakan rumus pada soal cerita berkaitan dengan keliling lingkaran, kesalahan mengutip rumus keliling lingkaran hal ini dikarenakan konsep pada keliling lingkaran tidak tertanam dalam diri siswa tersebut sehinngga siswa tidak memahami konsepnya dan hanya sekedar menghafal rumusnya saja.

Permasalahan yang lain berdasarkan pengamatan ditemukan di lapangan. Rencana Pelaksanaan Pembelajaran (RPP) Salah satu bahan ajar yang digunakan LKPD cetak pada kenyataannya LKPD yang telah dimiliki oleh siswa selama ini belum mampu membantu dalam menemukan konsep, karena hanya berisi materi dan soal-soal latihan saja. Selain itu ditinjau dari segi penyajiannya pun kurang menarik.

Model pembelajaran yang digunakan oleh guru masih menggunakan model pembelajaran konvensional tanpa adanya model pembelajaran yang bervariasi.Untuk mengemas model pembelajaran yang sesuai diperlukan keahlian bagi seorang pengajar.Tidak cukup hanya materi (content), atau kemampuan merancang pembelajaran (pedagogical) tetapi harus mampu menggabungkan keduanya. Kemampuan memanfaatan teknologi dalam pembelajaran (technological) juga harus dimiliki seorang guru.Kemampuan inilah yang sering 
disebut dengan TPACK (Technological Pedagogical and Content Knowledge) Dengan kemampuan ini diharapkan mampu menciptakan sebuah pembelajaran yang menarik untuk siswa. Agar tercapainya tujuan pembelajaran yang harapkan).

Untuk mengelaborasi peran teknologi, pedagogi dan materi pembelajaran digunakan kerangka kerja TPACK yang kompleks dan saling berhubungan antara komponen penyusunnya yaitu $(\mathrm{T}),(\mathrm{P})$, dan $(\mathrm{K})$ dalam proses pembelajaran. Hal ini menekankan hubungan dan kompleksitas antara tiga komponen sehingga terdapat keterkaitan antara $(P C K), \quad(T C K)$ dan (TPK) (Sutrisno, 2012:93).

Konsep dasar TPACK mengintegrasikan tiga komponen pengetahuan penting yang harus dimiliki sebagai pendidik yakni penguasaan materi, pedagogi dan teknologi(Sutrisno,2012).

Technology pedagogy and content knowledge(TPACK) diperkenalkan pertama kali oleh Koehler dan Mishra (2008). Mereka mendiskusikan TPACK sebagai kerangka kerja guru/pendesain dalam mengintegrasikan TIK dalam pembelajaran. Menurut Koehler dan Mishra(2008) TPACKberasaldari tiga sumberpengetahuan kunci yaitu technology knowledge (TK), pedagogy knowledge (PK), dan content knowledge $(C K)$. Mereka menggambarkannya dalam satu kesatuan yang saling terkait satu sama lain. Hal ini sejalan dengan tuntutan pembelajaran abad 21 dimana penguasaan TIK tidak bisa ditawartawar lagi terutama bagi guru. TPACK menekankan hubungan antara teknologi, isi kurikulum dan pendekatan pedagogi yang berinteraksi satu sama lain untuk menghasilkan pembelajaran berbasis TIK.Dalam skema TPACK terdapat hubungan antar komponen penyusun, saling beririsan antara materi $(\mathrm{C})$, pedagogi $(\mathrm{P})$ dan teknologi $(\mathrm{T})$ yang berpengaruh dalam konteks pembelajaran.Gambar dibawah ini memberkan ilustrasi terhadap hubungan ketiga komponen itu yaitu $\mathrm{C}$, $\mathrm{P}$ dan $\mathrm{T}$ yang selanjutnya $\mathrm{C}$ menjadi CK, P menjadi PK, dan T menjadi TK.

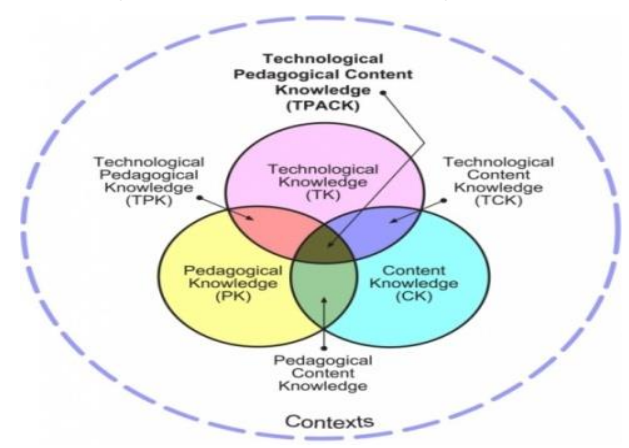

Gambar 1. Technology, pedagogy and content knowledge (TPACK) diadopsi dari

(Koehler dan Mishra, 2008)

Pemilihan alat bantu TIK disesuaikan dengan tujuan pembelajaran dan materi pembelajarannya agar siswa mendapatkan pengalaman belajar yang lebih bermakna sehingga siswa mampu menyelesaikan persoalan matematika. Dengan menggunakan media pembelajaran berbantuan animasi video dalam membantu siswa agar dapat memahami materi yang disampaikan oleh guru.

Peran teknologi pedagogi dan materi pembelajaran materi lingkaran untuk mengoptimalkan kemampuan penalaran dengan menggunakan model PBL dapat diintegrasikan dalam perangkat Pembelajaran berbasis TPACK. Perangkat pembelajaran berbasis TPACK dikembang kan sebagai solusi dari permasalahan yang dihadapi.

Adapun tujuan dalam penelitian ini adalah untuk menghasilkan perangkat pembelajaran berdasarkan kerangka TPACK untuk mengoptimalkan kemampuan penalaran deduktif siswa pada materi lingkaran. 


\section{METODE PENELITIAN}

Penelitian ini merupakan penelitian Penelitian ini merupakan penelitian pengembangan (Research and development) perangkat pembelajaran yang menggunakan kerangka kerja TPACK yang difokuskan pada pengembangan Rencana pelaksanaan pembelajaran (RPP) dan Lembar Kerja Siswa dalam bentuk flip page ebook yang disusun untuk meningkatkan kemampuan penalaran deduktif siswa.

Penelitian ini dirancang dengan menggunakan desain pengembangan model 4D yang disarankan oleh Thiagarajan, Semmel, dan Semmel (1974). Alasan penggunaan model ini adalah karena tahapannya yang sistematis dan lebih rinci.Model 4D terdiri dari 4 tahapan, yaitu define (pendefinisian), design (perancangan), develop (pengembangan), dan disseminate (penyebaran).

1. Tahap Pendefinisian (define)

Pada tahap ini pendefinisian dilakukan analisis kurikulum matematika SMP kelas VIII semester 2 khususnya dalam topik lingkaran. Analisis yang dilakukan meliputi mengidentifikasi Standar Inti (KI), Kompetensi Dasar (KD) sesuai dengan Kurikulum 2013 dan Indikator Pencapai Kompetensi. Hasil dari analisis yang dilakukan ini merupakan dasar dari proses pengembangan RPP dan LKPD yang dilakukan. Pada tahap ini juga dilakukan analisis yang lain sesuai prosedur pengembangan $4-\mathrm{D}$.

\section{Tahap Perancangan (desing)}

Pada tahap ini dilakukan penyesuaian RPP dan LKPD yang dikembangkan dengan pendekatan pembelajaran yang diterapkan. Selain itu juga dilakukan pengempulan dan penetuan referensi buku, menyusun rancangan RPP dan LKPD serta menyusun perangkat penilaian dari produk yang dikembagkan.

3. Tahap Pengembangan (develop)

Tahap pengembangan adalah proses untuk menghasilkan produk pengembangan yang dilakukan. Pada tahap ini dilakukan beberapa langkah yaitu pengembangan rancangan, validasi ahli (expert appraisal) yang diikuti dengan revisi dan ujioba pengembangan (develeopmet testing). tujuan tahap penembangan ini adalah untuk menghasilkan bentuk akhir RPP dan LKPD.

\section{Tahap Penyebaran (desiminate)}

Proses penyebaran merupakan tahap akhir dari suatu pengembangan. tahap ini dilakukan untuk mempromosikan produk pengembangan agar dapat diterima pengguna baik individu dan kelompok. Tetapi hanya keterbatasan waktu jadi produk yang dikembangkan hanya diadopsi dalam kelas dalam jumlah terbatas kepada guru dan peserta didik.

Instrumen yang digunakan dalam penelitian ini adalah lembar validasi, instrument, angket tanggapan siswa terhadap pembelajaran, dan lembar observasi aktivitas belajar siswa, soalsoal evaluasi belajar siswa, angket tanggapan guru terkait perangkat pembelajaran dan pelaksanaannya, serta instrument kerangka kerja Data yang diperoleh dari angket dianalisis menggunakan skala numerical rating scale.

\section{HASIL PENELITIAN DAN PEMBAHASAN}

Hasil dari penelitian pengembangan ini berupa, Rencana Pelaksanaan Pembelajaran (RPP) Lembar Kerja Peserta Didik (LKPD) dalam bentuk flip page ebook yang 
dibuat dengan software $3 D$ pageflip professional pada materi lingkaran.

Pembelajaran dikembangkan dalam penelitian ini adalah perangkat pembelajaran matematika berupa rencana pelaksanaan pembelajaran (RPP), dan lembar kerja siswa (LKS) dalm bentuk flip page ebook.

Rancangan struktur isi rencana pelaksanaan pemebelajaran (RPP) yang dikembangkan adalah identitas meliputi nama sekolah, mata pelajaran, kelas, semester dan alokasi waktu; Standar Kompetensi disesuaikan dengan standar isi Kompetensi Dasar disesuaikan dengan standar isi Kurikulum 2013. Indikator pembelajaran merupakan penjabaran dari kompetensi dasar; Tujuan Pembelajaran disesuaikan dengan indikator, materi pembelajaran merupakan rangkuman materi yang akan dipelajari sesuai dengan kompetensi dasar yang sudah ditetapkan.

Pelaksaanaanpembelajaran

dilakukan sebanyak 6 kali pertemuan yakni pertemuan tatap muka, 1 kali pertemuan kegiatan evaluasi yaitu ulangan harian.

Peserta Didik ( LKPD) dalam bentuk flip page ebook yang dibuat dengan software $3 D$ pageflip,berisikan materi pembelajaran, video yang menggunakan cabri $3 D$, video animasi, besertatugas kelompok serta soal-soal penilaian kemampuan penalaran siswa yang dibuat secara rinci dengan menggunakan teknologi.

Lembar Kerja Peserta Didik ( LKPD) dalam bentuk flip page ebook yang dibuat dengan software $3 D$ pageflip,materi pembelajaran, video yang menggunakan cabri $3 D$, video animasi, beserta, tugas kelompok, serta soal-soal penilaian kemampuan penalaran siswa yang dibuat secara rinci dengan menggunakan teknologi.
Metode penelitian dilakukan dengan cara uji coba yang dimulai dari uji coba perorangan, setelah mendapatkan saran dan masukan dari siswa terhadap produk yang dikembangkan, direvisi sesuai dengan saran dan masukan tersebut. Setelah direvisi dilakukan lagi uji coba kelompok kecil, dan selanjutnya uji coba kelompok besar.

Dari hasil uji coba perorang secara keseluruhan berkatagori optimal tetapi secara keseluruhan berkomentar positif tentang LKPD yang digunakan.kelompok kecil yang terdiri dari 6 orang secara keseluruhan berkometar sangat optimal tentang LKPD yang digunakan.uji coba kelompok besar terdiri 22 orang berkomentar sangat optimal.

Tabel 1. Persentase kemampuan penalaran

\begin{tabular}{cccccc}
\hline Persentase & \multicolumn{5}{c}{ Indikator } \\
\cline { 2 - 5 } Setiap & 1 & 2 & 3 & 4 & 5 \\
Indikator & $84 \%$ & $78 \%$ & $87 \%$ & $65 \%$ & $75 \%$ \\
\hline Rata-Rata & \multicolumn{5}{c}{$74,77 \%$} \\
Persentase & \multicolumn{5}{|c}{} \\
\hline
\end{tabular}

Keterangan:

1. Indikator menyajikan matematika secara lisan tertulis

2. Indikator melakukan manipulasi matematika

3. Menarik kesimpulan

4. Menarik kesimpulan, memberikan alasan atau bukti

5. Memeriksa kesahihan suatu argument

Tabel 1 yaitu rata-rata persentase kemampuan penalaran deduktif siswa secara keseluruhan adalah $74,77 \%$ yang termasuk kategori optimal.Walaupun persentase kemampuan penalaran sudah kategori optimal, tetapi kemampuan ini masih bisa ditingkatkan lagi apabila guru selalu melatih siswa untuk bisa bernalar dengan baik. Kemampuan bernalar sangat dibutuhkan bagi siswa 
ISSN 2089-8703 (Print) Vol. 7, No. 3 (2018) 403-412

ISSN 2442-5419 (Online)

maupun mahasiswa dalam memahami materi atau konsep matematika

Instrumen yang digunakan adalah angket TPACK untuk mengukur TPACK guru berupa angket tertutupdengan jumlah item pernyataan mewakili ke empat (4) komponen TPACK yaitu TK, PK, CK, dan TPACK.

Hubungan antar komponen CK (Conten Knowledge), (TK (Technology
Pedagogy), PK (Pedagogy Knowledge), TPCK (Technology Pedagogy Conten Knowledge) dan kemampuan penalaran siswa pada materi lingkaran.

Hubungan antar komponen CK (Conten Knowledge), (TK (Technology Pedagogy), PK (Pedagogy Knowledge), TPCK (Technology Pedagogy Content Knowledge) dan kemampuan penalaran siswa. hasil korelasi dapat dilihat pada Tabel 2.

Tabel 2. Hasil Korelasi CK, TK, PK, TPACK Terhadap Kemampuan Penalaran Deduktif Correlations

\begin{tabular}{|c|c|c|c|c|c|c|}
\hline & & CK & TK & PK & TPACK & $\begin{array}{l}\text { Kemapuan } \\
\text { Penalaran }\end{array}$ \\
\hline \multirow[t]{3}{*}{ CK } & $\begin{array}{l}\text { Pearson } \\
\text { Correlation }\end{array}$ & 1 &,$- 274^{*}$ &, $224^{*}$ &,- 215 &, $387^{* *}$ \\
\hline & Sig. (2-tailed) & & ,014 & ,046 & 056 & ,000 \\
\hline & $\mathrm{N}$ & 80 & 80 & 80 & 80 & 80 \\
\hline \multirow[t]{3}{*}{ TK } & $\begin{array}{l}\text { Pearson } \\
\text { Correlation }\end{array}$ &,$- 274^{*}$ & 1 &,- 147 & ,075 &,$- 346^{* *}$ \\
\hline & Sig. (2-tailed) & ,014 & & ,194 & ,506 & ,002 \\
\hline & $\mathrm{N}$ & 80 & 80 & 80 & 80 & 80 \\
\hline \multirow[t]{3}{*}{ PK } & $\begin{array}{l}\text { Pearson } \\
\text { Correlation }\end{array}$ & $224^{*}$ &,- 147 & 1 &,$- 409^{* * *}$ &, $377^{* * *}$ \\
\hline & Sig. (2-tailed) & ,046 & 194 & & ,000 & ,001 \\
\hline & $\mathrm{N}$ & 80 & 80 & 80 & 80 & 80 \\
\hline \multirow[t]{3}{*}{ TPACK } & $\begin{array}{l}\text { Pearson } \\
\text { Correlation }\end{array}$ &,- 215 & ,075 &,$- 409^{* * *}$ & 1 & ,059 \\
\hline & Sig. (2-tailed) & ,056 & ,506 & ,000 & & 602 \\
\hline & $\mathrm{N}$ & 80 & 80 & 80 & 80 & 80 \\
\hline Kemapuan & Pearson &, $387^{* *}$ &,$- 346^{* *}$ &, $377^{* *}$ & ,059 & 1 \\
\hline \multirow{3}{*}{ Penalaran } & Correlation & & & & & \\
\hline & Sig. (2-tailed) & ,000 & ,002 & ,001 & ,602 & \\
\hline & $\mathrm{N}$ & 80 & 80 & 80 & 80 & 80 \\
\hline
\end{tabular}

Untuk melihat hubungan secara linear atau tidaknya maka dapat dilakukan analisis regresi dalam analisis jalur terhadap 2 bentuk jalur rantai yang digunakan 
ISSN 2089-8703 (Print) Vol. 7, No. 3 (2018) 403-412

ISSN 2442-5419 (Online)

a. Jalur TPACK

Tabel 3 Anova Jalur TPACK

\begin{tabular}{|c|c|c|c|c|c|c|c|c|c|c|c|c|c|}
\hline & \multirow[b]{3}{*}{ Model } & \multicolumn{7}{|c|}{ Coefficients $^{\mathrm{a}}$} & & & & & \\
\hline & & \multicolumn{2}{|c|}{$\begin{array}{l}\text { Unstandardized } \\
\text { Coefficients }\end{array}$} & \multirow[t]{2}{*}{$\begin{array}{l}\text { Standardized } \\
\text { Coefficients }\end{array}$} & \multirow[b]{2}{*}{$\mathrm{t}$} & \multirow[b]{2}{*}{ Sig. } & \multicolumn{2}{|c|}{$\begin{array}{c}95,0 \% \\
\text { Confidence } \\
\text { Interval for B }\end{array}$} & \multicolumn{3}{|c|}{ Correlations } & \multicolumn{2}{|c|}{$\begin{array}{l}\text { Collinearity } \\
\text { Statistics }\end{array}$} \\
\hline & & & $\begin{array}{l}\text { Std. } \\
\text { Error }\end{array}$ & & & & $\begin{array}{l}\text { Lower } \\
\text { Bound }\end{array}$ & $\begin{array}{l}\text { Upper } \\
\text { Bound }\end{array}$ & $\begin{array}{l}\text { Zero- } \\
\text { order }\end{array}$ & Partial & Part & Tolerance & VIF \\
\hline \multirow[t]{4}{*}{1} & (Constant) & 2.239 & 1.001 & & 2.237 & .028 & .245 & 4.234 & & & & & \\
\hline & CK & -.114 & .097 & -.117 & $1.177^{-}$ & .243 & -.306 & .079 & -.215 & -.137 & $\begin{array}{r}- \\
.109\end{array}$ & .858 & 1.165 \\
\hline & TK & -.044 & .113 & -.038 & -.393 & .696 & -.269 & .180 & .075 & -.046 & $.03 \overline{6}$ & .906 & 1.104 \\
\hline & PK & -.275 & .148 & -.207 & 1.861 & .067 & -.569 & .020 & -.409 & -.213 & .172 & .688 & 1.454 \\
\hline
\end{tabular}

b. Jalur Kemampuan Penalaran Deduktif

Tabel 4. Model Summary Kemampuan Penalaran Deduktif

\begin{tabular}{|c|c|c|c|c|c|c|c|c|c|c|}
\hline \multirow[b]{2}{*}{ Model } & \multirow[b]{2}{*}{$\mathrm{R}$} & \multirow[b]{2}{*}{$\begin{array}{c}\mathrm{R} \\
\text { Square }\end{array}$} & \multirow[b]{2}{*}{$\begin{array}{l}\text { Adjusted } \\
\text { R Square }\end{array}$} & \multirow{2}{*}{$\begin{array}{c}\text { Std. } \\
\text { Error of } \\
\text { the } \\
\text { Estimate }\end{array}$} & \multicolumn{5}{|c|}{ Change Statistics } & \multirow[b]{2}{*}{$\begin{array}{l}\text { Durbin- } \\
\text { Watson }\end{array}$} \\
\hline & & & & & $\begin{array}{c}\text { R Square } \\
\text { Change }\end{array}$ & $\begin{array}{c}\text { F } \\
\text { Change }\end{array}$ & df1 & df2 & $\begin{array}{c}\text { Sig. F } \\
\text { Change }\end{array}$ & \\
\hline 1 &, $604^{\mathrm{a}}$ &, 364 & ,330 & ,86954 & ,364 & 10,744 & 4 & 75 & ,000 & ,644 \\
\hline
\end{tabular}

a. Predictors: (Constant), TPACK, TK, CK, PK

b. Dependent Variable: kemapuan penalaran

Pada Tabel 4 model summary nilai $R$ square atau disebut koefisen diterminasi adalah 0,364 atau 3,64\%. Nilai tersebut menunjukkan bahwa besarnya pengaruh $\mathrm{CK}$ (Conten Knowledge), (TK (Technology Pedagogy), PK (Pedagogy Knowledge), TPCK (Technology Pedagogy Conten
Knowledge) dan Kemampuan Penalaran Deduktif. Sebesar 3,64\%, sedangkan sisanya di pengaruhi oleh variabel lain $\left(e_{2}\right)$ yakni $100 \%-3,64 \%=96,36 \%$.

Dari gambar analisis jalur yang telah diusulkan, sesuai hitungan analisi jalur maka diagram jalur yang diusulkan dapat disajikan sebagai berikut 
ISSN 2089-8703 (Print) Vol. 7, No. 3 (2018) 403-412

ISSN 2442-5419 (Online)

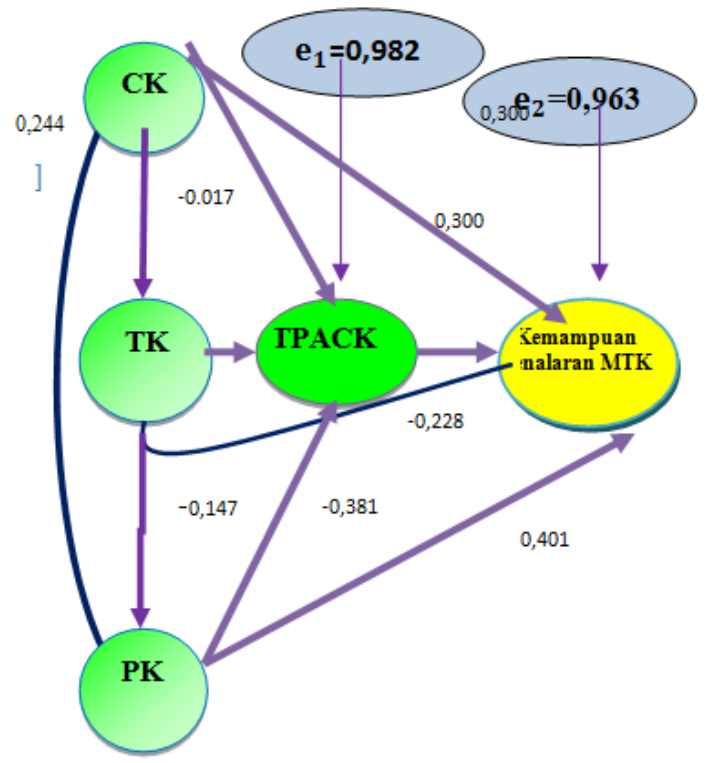

Gambar 2. Diagram jalur TPACK Kemampuan Penalaran Deduktif

Kemampuan penalaran deduktif dapat ditentukan koefisien pengaruh langsung dan pengaruh total sebagai berikut:

Pengaruh langsung adalah pengaruh dari variabel CK,TK,PK terhadap TPACK dari varibel TPACK terhadap kemampuan penalaran deduktif secara sederhana disajikan sebagai berikut:

a. Pengaruh $C K$ terhadap $T P A C K=-$ 0,134

b. Pengaruh $T K$ terhadap $T P A C K=-$ 0,017

c. Pengaruh $P K$ terhadap $T P A C K=-$ 0,381

Pengaruh total terhadap CK, TK, PK, terhadap kemampuan penalaran sebagai berikut.

$\mathrm{CK}=C K$ langsung $+C K$ tidak langsung $=0,314$

Pengaruh total TK terhadap kemampuan penalaran deduktif TK Langsung + TK Tidak Langsung= 0,113 . Jadi pengaruh total TK terhadap kemampuan penalaran deduktif adalah sebesar 0,113. Pengaruh total PK terhadap kemampuan penalaran deduktif

PK Langsung + PK Tidak Langsung $=(0,401)^{2}+(0,401 \times-0,381 \times$ $0,305)$

$=0,160+(-0,046)$

$=0,114$

Jadi pengaruh PK terhadap kemampuan penalaran deduktif adalah sebesar 0,114.

Hal ini sejalan dengan penelitian yang dilakukan oleh Rahmini (2013) yaitu pengembangan perangkat pembelajaran matematika berdasarkan kerangka kerja TPACK pada materi bangun ruang sisi lengkung dapat mengoptimalkan keterampilan berfikir kritis siswa.

Penelitian terkait lainnya adalah penelitian yang dilakukan oleh (Mairiska, Sutrisno, \& Asrial, 2014) yaitu penelitian pengembangan perangkat pembelajaran berbasis TPACK pada materi sifat koligatif larutan, tujuan penelitian adalah untuk mengembangkan Rencana Pelaksanaan Pembelajaran (RPP) dan Lembar Kerja Siswa (LKS) dalam bentuk 
flip page ebook, menerapkan RPP dan LKS tersebut serta menganalisis keterkaitan antar komponen penyusun TPACK. Penelitian ini menggunakan desain pengembangan Model 4D Thiagarajan, Semmel dan Semmel Model, yang telah dimodifikasi. Hasil penelitian menunjukkan aktivitas pembelajaran pada pertemuan I 92\%, pertemuan II dan III $93,4 \%$, pertemuan IV dan V $86,7 \%$, pertemuan VI $86,1 \%$, pertemuan VII $91,4 \%$, ketujuh pertemuan

tersebut termasuk pada kategori "sangat optimal". Siswa memberikan tanggapan positif terhadap pembelajaran dan produk yang dikembangkan. Rata-rata persentase keterampilan berpikir kritis siswa secara keseluruhan adalah $66,3 \%$ yang termasuk ke dalam kategori baik.

Penelitian Puspitarini, dkk (2013) dengan penelitian pemodelan Technological Pedagogical Content Knowledge (TPACK) Berbasis Teknologi Informasi Dan Komunikasi (TIK) Dengan Pendekatan Structural Equation Modeling (SEM) bahwa hasil peneiltian ini mengenai variabel mana yang paling berpengaruh dalam TPACK pada obyek penelitian ini yaitu guru pengajar mata pelajaran UN (Matematika, IPA, Bahasa Indonesia, Bahasa Inggris) di kabupaten Pasuruan. Tahapan yang dilalui mulai dari proses observasi dan survey, kemudian pembuatan kuesioner sebagai indikator dari variabel laten pembentuk TPACK.

Handy darmawan (2016) melakukan penelitian tentang pembelajaran berbasis konstruktivisme menggunakan media animasi dengan kerangka kerja TPACK dan gaya belajar terhadap prestasi belajar siswa. Bahwa hasil peneilitian terdapat pengaruh pembelajaran berbasis konstruktivisme menggunakan media animasi terhadap prestasi belajar siswa, tidak terdapat pengaruh gaya belajar terhadap prestasi belajar siswa, terdapat pengaruh penggunaan media animasi dan gaya belajar terhadap prestasi belajar siswa.

Hasil penelitian menunjukkan bahwa guru mengalami kesulitan mengintegrasi kan pengetahuan pedagogis mereka kedalam teknologi selama proses desain kegiatan dan memiliki kekurangan dalam hal TPACK.

\section{KESIMPULANDAN SARAN}

Berdasarkan hasil penelitian yang telah dilakukan maka dapat disimpulkan bahwa perangkat pembelajaran matematika kerangka kerja TPACK bahwa komponen Technology Content Knowledge (TCK) mempunyai pengaruh paling besar terhadap kemampuan penalaran deduktif. Saran yang harus dilakukan yaitu penguasaan pedagogi yang bervariasi, mampu merancang pembelajaran yang tidak hanya menitik beratkan pada hasil belajar, tetapi juga aktivitas belajar, dan keterampilan berpikir tingkat tinggi siswa.

\section{DAFTAR PUSTAKA}

Atasoy, E., Uzun, N. \& Aygun, B. (2016). Technological pedagogical content knowledge of prospective mathematics teachers regarding evaluation and assessment. World Journal on Educational Technology. 8(1), 1824.

Darmawan, H. (2016). Pembelajaran berbasis kontruktifesme menggunakan media animasi dengan kerangka kerja TPCK dan gaya belajar terhadap prestasi belajar siswa. IKIP-PGRI Pontianak

Goradia, T. (2018). Role of Educational Technologies Utilizing the 
TPACK Framework and 21st Century Pedagogies: Academics' Perspectives. IAFOR Journal of Education 6 (3)

Jaipal-Jamani, K, Figg, C., Collier, D., Gallagher, T., Winters, K., \& Ciampa, K. (2018). Developing TPACK of university faculty through technology leadership roles. Italian Journal of Educational Technology, 26(1), 39-55 doi: 10.17471/2499$4324 / 984$

Koehler, M. \& Mishra. (2008). Handbook of Technological Pedagogical Content Knowladge (TPCK) for Educators, Routledge for the American Association of Colleges for Teacher Education, New York

Lu, L. (2014). Cultivating Reflective Practitioners in Technology Preparation: Constructing TPACK through Reflection. Educ. Sci. 2014, 4, 13-35; doi:10.3390/educsci4010013

Mairiska, T., Sutrisno, \& Asrial. (2014). Pengembangan Perangkat Pembelajaran Berbasis TPACK pada Materi Sifat Koligatif Larutan untuk Meningkatkan Keterampilan Berpikir Kritis Siswa. Jurnal Edu-Sains, 3(1), 28-35

Puspitarini, E.W., dkk. (2013). Pemodelan technological content knowlodge (TPACK) berbasis teknologi informasi dan komunikasi (TIK) dengan pendekatan structural equation modeling (SEM). Prosiding Seminar Nasional Manajemen Teknologi XVIII.Surabaya

\section{Rahmini. (2014). Pengembangan Perangkat Pembelajaran Matematika Berdasarkan Kerangka Kerja TPACK pada materi bangun ruang sisi lengkung untuk mengoptimalkan keterampilan berpikir kritis siswa. Tesis magister, tidak diterbitkan, Universitas Jambi, Jambi}

Soleh, N., Rochmad, \& Supriyono. (2014). Kemampuan penalaran deduktif siswa kelas VII pada pembelajaran model-eliciting activities. Unnes Journal of Mathematics Education, 3 (1),3540.

Sutrisno. $2012 . \quad$ Kreatif Mengembangkan Aktivitas Pembelajaran Berbasis TIK. Jakarta. Referensi

Sumarsono, T., Malik, A., \& Sutrisno. (2012). Penerapan kerangka "TPACK" dan konten pembelajaran "blended learning" untuk meningkatkan aktifitas pembelajaran mahasiswa. Proceeding Seminar Nasional Cakrawala Pembelajaran Berkualitas Di Indonesia. Universitas Jambi

Thiagarajan, S., Semmel, D. S \& Semmel, M. I. (1974). Instructional Development for Training Teachers of Exceptional Children: A Sourcebook. Minneapolis, Minnesota: Leadership Training Institute/Special Education, University of Minnesota. 